Discussion Paper No. 04-63

Reduction in the Long-Term Unemployment of the Elderly:

A Success Story from Finland

Tomi Kyyrä and Ralf A. Wilke

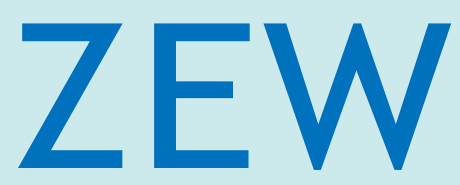

Zentrum für Europäische Wirtschaftsforschung $\mathrm{GmbH}$

Centre for European

Economic Research 
Discussion Paper No. 04-63

\title{
Reduction in the Long-Term Unemployment of the Elderly: A Success Story from Finland
}

\author{
Tomi Kyyrä and Ralf A. Wilke
}

Download this ZEW Discussion Paper from our ftp server:

ftp://ftp.zew.de/pub/zew-docs/dp/dp0463.pdf

Die Discussion Papers dienen einer möglichst schnellen Verbreitung von neueren Forschungsarbeiten des ZEW. Die Beiträge liegen in alleiniger Verantwortung der Autoren und stellen nicht notwendigerweise die Meinung des ZEW dar.

Discussion Papers are intended to make results of ZEW research promptly available to other economists in order to encourage discussion and suggestions for revisions. The authors are solely responsible for the contents which do not necessarily represent the opinion of the ZEW. 


\section{Non-technical Summary}

In European countries unemployment levels are typically higher and unemployment durations are often longer than in the United States. These unemployment differences have been the focus of much political and academic debate in recent years. The unemployment compensation system, with more generous benefit levels and longer entitlement periods, is often blamed to be responsible for much of the European unemployment problem. In this paper we show that this is indeed true for a large share of the long-term unemployment of the elderly in Finland.

Among the European countries Finland has performed relatively poorly in terms of unemployment. As a consequence of the deep depression in the early 1990s, the Finnish unemployment rate peaked to almost 20 percent in 1994. Despite rapid economic growth over the latter part of the 1990s, unemployment has stuck at a high level and the fraction of the long-term unemployed has increased alarmingly. As in other European countries, such as Germany and France, the share of elderly long-term unemployed is large. The Finish unemployment tunnel scheme is often blamed to be responsible for that. This scheme allows the elderly unemployed to collect unemployment benefits up to the age of 60, when they can retire via a particular unemployment pension. In 1997 the eligibility age of this scheme was raised from 53 to 55 . We consider changes in the risk of unemployment, unemployment durations, and the exit states before and after the reform. In the duration analysis a flexible treatment design is adopted by allowing for quantile treatment effects. We apply three different non- and semiparametric methods, which all produce robust and coherent results. After the reform the group aged 53-54 has a lower risk of unemployment, shorter unemployment durations, higher exit rates to employment and it is not anymore distinguishable from the group aged 50-52. We

provide calculations of the expected save in unemployment benefit transfers due to the reform and found that it is in the range of 100 million euros per age cohort. 


\title{
Reduction in the Long-Term Unemployment of the Elderly: A Success Story from Finland*
}

\author{
Tomi Kyyrä (VATT) $)^{\dagger}$ and Ralf Wilke $(\text { ZEW) })^{\ddagger}$
}

September 30, 2004

\begin{abstract}
In Finland the elderly unemployed are allowed to collect unemployment benefits up to the age of 60 , when they can retire via a particular unemployment pension. In 1997 the eligibility age of persons benefiting from this scheme was raised from 53 to 55 . We consider changes in the risk of unemployment, unemployment durations, and the exit states before and after the reform. In the duration analysis a flexible treatment design is adopted by allowing for quantile treatment effects. We apply three different non- and semiparametric methods, which all produce robust and coherent results. Since the reform the group aged 53-54 has had a lower risk of unemployment, shorter unemployment durations, and higher exit rates to employment, and it is no longer distinguishable from the group aged 50-52. We estimate the amount of unemployment benefits saved due to the reform.
\end{abstract}

Keywords: Unemployment insurance reform, quantile treatment effect, non- and semiparametric methods, Finnish register data.

JEL classification: J64, J26, C14, C41.

*This paper has benefited from the comments received at the seminar at Mannheim University, the Semiparametrics in Rio Conference, the ESEM Conference in Madrid, and the EALE Conference in Lisbon. Financial support from the German Research Foundation (DFG) through the project "Microeconometric modelling of unemployment durations under consideration of the macroeconomic situation" is gratefully acknowledged. We thank Xuan Zhang and Ossi Korkeamäki for their research assistance and Bernd Fitzenberger, Antti Romppanen, Juha Rantala, and Tuulia Hakola for their suggestions and comments. All manipulations of confidential data from Statistics Finland have been performed by authorised persons only.

${ }^{\dagger}$ The Government Institute for Economic Research (VATT), P.O.Box 1279, FIN-00101 Helsinki, Finland; E-mail: tomi.kyyra@vatt.fi

‡ZEW Mannheim, P.O.Box 1034 43, 68034 Mannheim, Germany; E-mail: wilke@zew.de 


\section{Introduction}

Unemployment differences between the European countries and the United States have been the focus of much political and academic debate in recent years. In addition to higher unemployment levels, the durations of unemployment spells are typically much longer in Europe than in the US. The unemployment compensation system, with more generous benefit levels and longer entitlement periods, is often blamed for being responsible for much of the European unemployment problem. Among the European countries Finland has performed relatively poorly in terms of unemployment. As a consequence of the deep depression in the early 1990s, the Finnish unemployment rate peaked at almost 20 percent in 1994. Despite rapid economic growth over the latter part of the 1990s, unemployment has stuck at a high level and the fraction of the long-term unemployed has increased alarmingly.

In Finland unemployment benefits can be received for a maximum of two years, but there is an exception for the older unemployed. Workers aged 55 (53 before 1997) or more at the time of job loss are allowed to collect unemployment benefits up to the age of 60 , when they become eligible for the unemployment pension benefit. At the age of 65 the unemployment pension is transformed into the normal old-age pension. This route out of the labour market is widely known as the "unemployment tunnel". The unemployment tunnel (UT) scheme contributes to aggregate unemployment in two ways. First, the employers tend to target dismissals at the elderly workers, as a reasonable income level is fully secured for them. Rantala (2002) provides evidence that the unemployment risk as a function of age at least doubles at the eligibility age of the UT scheme. Secondly, without a risk of future cuts in the benefit level, the elderly unemployed may be more passive in job search and be more choosy in accepting job offers, leading to longer unemployment spells. Not surprisingly, the older cohorts account for a large fraction of the aggregate unemployment rate. In 2000 one-third of the unemployed (including those on the unemployment pension) and two-thirds of the long-term unemployed were aged 56 and over (Koskela and Uusitalo, 2003).

In practice, the UT scheme facilitates the withdrawal of the aged workers from the labour market several years before the official retirement age of 65 . This is in clear contrast with the government's goal of inducing people to retire later. The effective retirement age in Finland is currently around 60, five years below the official retirement age. The Finnish pension system is built in such a way that the pensions of the retired are paid in large part by the current employees. As the Finnish 
population will age more rapidly than most of the other European populations over the next few decades, ${ }^{1}$ the financing of the future pensions has been a subject of increasing concern. As a result of economic pressures, several policy measures have been taken to discourage early retirement. These measures included an increase in the age threshold for the UT scheme: the eligibility age for the extended benefit entitlement period, which is followed by the unemployment pension at the age of 60, was increased from 53 to 55 in 1997. Consequently, the unlimited entitlement period of unemployment benefits of the age group 53-54 was effectively reduced to the maximum of two years, while the other age groups remained unaffected by the reform. In this paper we examine the effect of this reform on the incidence and duration of unemployment among elderly workers.

We employ high-quality panel data drawn from the records of the Finnish Employment Statistics database. This database includes information from several administrative registers, and it effectively covers the entire Finnish population. In the first stage we quantify the change in the inflow to unemployment resulting from the increase in the age threshold of the UT scheme. This effect turns out to be very strong. In the second stage we examine the effect of the UT reform on the distribution of unemployment durations. Following Doksum (1974), we define the treatment effect as a horizontal distance between the marginal distributions of unemployment durations for the treatment group (i.e. 53-54 years old in 1996) and the comparison group (i.e. 53-54 years old in 1997). In other words, we consider the effect of the reform across the different quantiles of the unemployment duration distribution. In the duration analysis we apply the Kaplan-Meier estimator, a stratified version of the competing risks Cox proportional hazard $(\mathrm{PH})$ model, and the quantile regression method to a sample of people between the ages of 50 and 57 who became unemployed in 1996 or 1997. Unlike in the difference-in-differences approach with dummy variables added to the proportional hazard model as in Hunt (1995) and Carling et al. (2001), we do not require the treatment effect to be proportional with respect to the transition rate to employment. In the (censored) quantile regression model, nonproportionality of the reform effect is easily accounted for by allowing the coefficient of the treatment dummy - and those of all other covariates - to vary across the quantiles. All the three flexible estimation approaches produce robust and coherent results. The probability of re-employment increased from 20 to 70

\footnotetext{
${ }^{1}$ The old-age dependency ratio, i.e. the ratio of the population aged 65 and over to the population aged 20-64, is estimated to rise from the current level of $25 \%$ to over $40 \%$ by 2025 , when Finland is expected to have the second highest dependency ratio among the OECD countries (OECD, 2004, pp. 18-20).
} 
percent for the age group affected by the UT reform. After the reform, differences in the unemployment duration distributions between the age groups 53-54 and 50-52 vanished. In the final stage of the analysis we quantify the amount of unemployment benefit saved owing to the increase in the UT age threshold and find it to be around 100 million euros for each age cohort.

The rest of the paper proceeds as follows. In the next section we describe the Finnish unemployment compensation system and early retirement schemes, with an emphasis on the UT scheme. Section 3 gives details of the data and reports some sample statistics. Section 4 discusses the econometric methods and presents the results. The final section concludes.

\section{The Institutional Framework}

We shall discuss the features of the Finnish social security system during the second half of the 1990s, i.e. around the time of our empirical analysis. It should be stressed that the Finnish system has been the subject of continuous changes over the years. A more complete description of the regulations and current reforms affecting early retirement is provided by OECD (2004).

\subsection{The unemployment compensation system}

The Finnish compensation system distinguishes between the basic unemployment allowance, earnings-related unemployment insurance (UI) benefit, and labour market support. The earnings-related UI benefit is received by workers who have been in work and contributed insurance payments to an unemployment fund for at least 10 months during the two years prior to unemployment. ${ }^{2}$ Those who fulfil the employment criteria, i.e. having worked at least 10 months, but do not belong to any unemployment fund are eligible only for the basic allowance (which amounts to 115 euro per week in 2003). The replacement rate for the earnings-related UI benefit declines with the level of the former earnings, the gross and net replacement rates for a worker with median earnings being 55 and 64 percent respectively (Koskela and Uusitalo, 2003). The basic allowance and UI benefit can be received for a maximum of two years, i.e. 500 working days, but an exception is made for the elderly (see below). Workers who do not meet the employment criteria or whose entitlement period has been exhausted can claim labour market support, which is viewed as

\footnotetext{
${ }^{2}$ The unemployment funds are closely related to labour unions. The fund membership is voluntary, and workers can join the fund without joining the union.
} 
a minimum income for the long-term unemployed and those who are entering the labour market. The maximum benefit level for labour market support equals the basic unemployment allowance, but it is means-tested against household income.

\subsection{Early retirement schemes and the unemployment tunnel}

Disability and unemployment pensions are the major pathways of early withdrawal from the labour market. ${ }^{3}$ The disability pension is payable to people between the ages of 16 and 65 who are unable to support themselves by regular work because of deteriorated health. Although receipt of a disability pension is conditional on a medical assessment, almost one-fifth of all people aged 55 to 64 were on a disability pension in 2001 (Rantala and Romppanen, 2004). Compared with most of the other OECD countries, the incidence of disability among older people seems to be especially high in Finland (OECD, 2004, p. 58). The disability pension provides a benefit level comparable to normal old-age pension benefits, which may partly explain its popularity. The unemployment pension is payable to a person aged between 60 and 64 who has been unemployed and has collected unemployment benefits for at least two years. The compensation level of the unemployment pension is close to other early retirement schemes and usually exceeds the level of UI benefit. ${ }^{4}$ At the age of 65 unemployment and disability pensions are transformed into normal old-age pensions.

Moreover, the unemployed who turn 57 (55 before 1997) during their unemployment benefit entitlement period of two years are allowed to collect unemployment benefits up until the age of 60 . Thus an unemployed person aged 55 or over (53 or over before 1997) at the beginning of the unemployment spell has an option to collect unemployment benefits up to the entry into the unemployment pension scheme, which will be subsequently followed by a normal old-age pension. This combination of the extended unemployment benefit entitlement period and the unemployment pension has become known as the "unemployment tunnel". ${ }^{5}$

\footnotetext{
${ }^{3}$ Other early retirement schemes include early old-age pension, individual early retirement, parttime pension, and farmers' pensions. These schemes are of less importance and are not discussed here.

${ }^{4}$ The compensation levels of UI benefits and unemployment pensions are determined by previous earnings over the periods of different lengths. The UI benefits tend to be higher for workers with a steeply increasing earnings profile before job loss. Rantala (2003) finds that transitions from unemployment to the unemployment pension were followed by an average increase of 16 percent in the gross compensation level in 1996 and 1997.

${ }^{5}$ Over the period 2009-2014 the unemployment pension scheme will be gradually abolished and replaced with additional unemployment benefit days for the elderly until the age of 65 .
} 


\subsection{Incentives}

Large numbers of older workers have been found to withdraw from the labour market several years before the normal retirement age. This finding is related to the elements of the Finnish social security system that induce firms to focus workforce reductions on older workers on the one hand, and discourage the elderly unemployed from returning to work on the other hand. Consider the supply side first. As those who are eligible for the UT scheme cannot lose their unemployment benefits, they may be less active in searching for employment opportunities and claim higher wages. Additionally, since the old-age pension benefit is computed as a function of wages over the last ten working years, ${ }^{6}$ accepting a low wage can reduce future pension benefit and this may increase the wage claims of the older unemployed. It may also be difficult to find wage offers close to the previous wage level, as post-unemployment wages are generally clearly below the average wage level (see Holm et al., 1999). Overall, financial incentives to return to employment are rather poor for the elderly unemployed.

For the employer, keeping elderly workers can be a risky business. This is because employers are liable for a large fraction of early retirement expenditure via partially experienced-rated employer contributions. Experience-rating is not applied to firms with fewer than 50 employees, but larger firms have to pay a given proportion of the early pension benefit stream received by their former employees. This cost share is determined as a linear function of firm size. In the case of the unemployment pension, firms with over 300 employees pay a maximum amount of one-half of the overall cost, whereas medium-sized firms with 51-300 employees pay a lower share. A different scale is applied to the disability pension, in which case the former employer pays something between 0 (firms with fewer than 50 employees) and 100 (firms with more 1000 employees) percent of the early pension expenditures. In practice, the cost share of the disability pension exceeds that of the unemployment pension for firms with more than 500 employees. ${ }^{7}$ The opposite is true for firms with 51 to 500 employees, while it does not make any difference for smaller firms. It is worth emphasizing that costs incurred by the employer can cumulate over several years until the former employee reaches the age of 65 and transfers to an old-age pension. Once again, there is a difference between the two schemes: the unemployment pension costs cannot realize until the former employee turns 60 but the disability pension

\footnotetext{
${ }^{6}$ Old-age pension benefits will be calculated using life-time earnings for those who retire 2013 or later.

${ }^{7}$ The experience-ratings of the two early pension schemes were harmonized in 2000.
} 
costs may emerge much earlier.

It is evident that early retirement can become costly for the former employer, especially in the case of a large firm. This may induce firms to get rid of their elderly employees and to discriminate against older job applicants in recruitment. ${ }^{8}$ Discrepancies in experience-rating and timing of early retirement costs between disability and unemployment pensions may encourage economically distressed firms to lay off older workers. In doing so, the firm avoids the risk of incurring disability pension costs later, i.e. the risk that is rather high in the light of official statistics.

\section{$3 \quad$ Data and Descriptive Statistics}

We have daily information on the employment status of the entire Finnish population over a number of years. This sort of comprehensive data is available for economic research mainly in the Nordic countries, where the collection and maintenance of large-scale administrative registers, with unique identification information, has a long tradition. With the high-quality register data, researches can draw sizeable samples from the population of interest and get rid of response bias and most measurement error issues, which are common problems in survey-based data.

\subsection{The Employment Statistics database}

Our data were drawn from the records of the Employment Statistics (ES) database of Statistics Finland. Since 1987 the ES database has been updated regularly by the merging of information from over 20 administrative registers through the use of unique personality identity numbers. The ES database effectively covers all people with permanent residence in Finland, and its information content is extensive. Along with standard socio-demographic background variables, the database includes detailed information on annual incomes (from the tax authorities), periods in unemployment and active labour market policy programmes (from the employment offices), and job spells (from the pension institutes). With this source of data one can basically follow the entire Finnish population over time and across different labour market states. For research purposes the records of the ES database are currently available for the period 1988-2000.

\footnotetext{
${ }^{8}$ Age-dependent social security contributions further raise the costs of older workers compared with prime-age workers. In 2003, the contribution paid by the employer on top of the wage received by the worker varied from 19.3 to 38.4 percent, being an increasing function of firm size and the worker's age (OECD, 2004, p. 82).
} 


\subsection{The incidence of unemployment}

In the following analysis we focus on private sector workers only. The UT scheme is of less importance in the public sector, where employers have less strong financial incentives for age discrimination and workers with a long employment history gain from a high level of job security. Figure 1 displays the risk of becoming unemployed by age for various years in the private sector. The unemployment risk corresponds to a proportion of workers who were continuously employed over the past two years but who became unemployed or participated in an active labour market policy (ALMP) programme during the current year. ${ }^{9}$ This group of workers, with a relatively stable employment history, is eligible for unemployment benefits in the case of job loss, and hence exposed to the UT scheme. These workers are also very likely to be members of unemployment funds, and thereby eligible for the earnings-related UI benefits.

Before 1997 those who were 53 or older at the beginning of their unemployment period were eligible for the extended period of unemployment benefits, owing to the UT scheme. In 1994, 1995, and 1996 the likelihood of unemployment jumped at the age of 53 , increasing thereafter smoothly up to the age of 58 . In each year the unemployment risk starts to decline at around the age of 60 , suggesting that the oldest workers can exit from the labour market through other early retirement schemes. At the beginning of 1997 the age threshold for the UT scheme was raised from 53 to 55 . As a result, the unemployment risk as a function of age shifted two years ahead in 1997 and 1998 compared with the earlier years. In particular, the risk of unemployment in the age group 53-54 dropped to a level identical to that of age groups that were a few years younger. This clearly indicates that the sharp level shift in the unemployment risk after a given age cannot be a coincidence but is driven by the UT scheme. Since the incidence of unemployment did not (at least) increase among workers aged 55 and over after the reform, there is no evidence of spillover effects on older groups.

It seems to be the rule rather than the exception that large reductions in the workforce are carried out using a combination of layoffs and early retirement arrangements, including the use of the UT scheme. It is hard to explain this phenomenon

\footnotetext{
${ }^{9}$ More specifically, the risk of unemployment in year $t$ for $k$ years old workers is computed as

$$
1-\prod_{m=1}^{12}\left[1-p_{t, m}(k)\right]
$$

where $p_{t, m}(k)$ is the monthly layoff rate among workers aged $k$ at the end of month $m$ in year $t$, which is defined as the ratio of workers unemployed (and those participating in ALMP programmes) at the end of month $m$ who were employed from the beginning of year $t-2$ to the end of month $m-1$ in year $t$ to otherwise equal workers but who were still employed at the end of month $m$.
} 
Figure 1: Unemployment risk by age and year in the private sector (Source: the authors' calculations from the ES database)

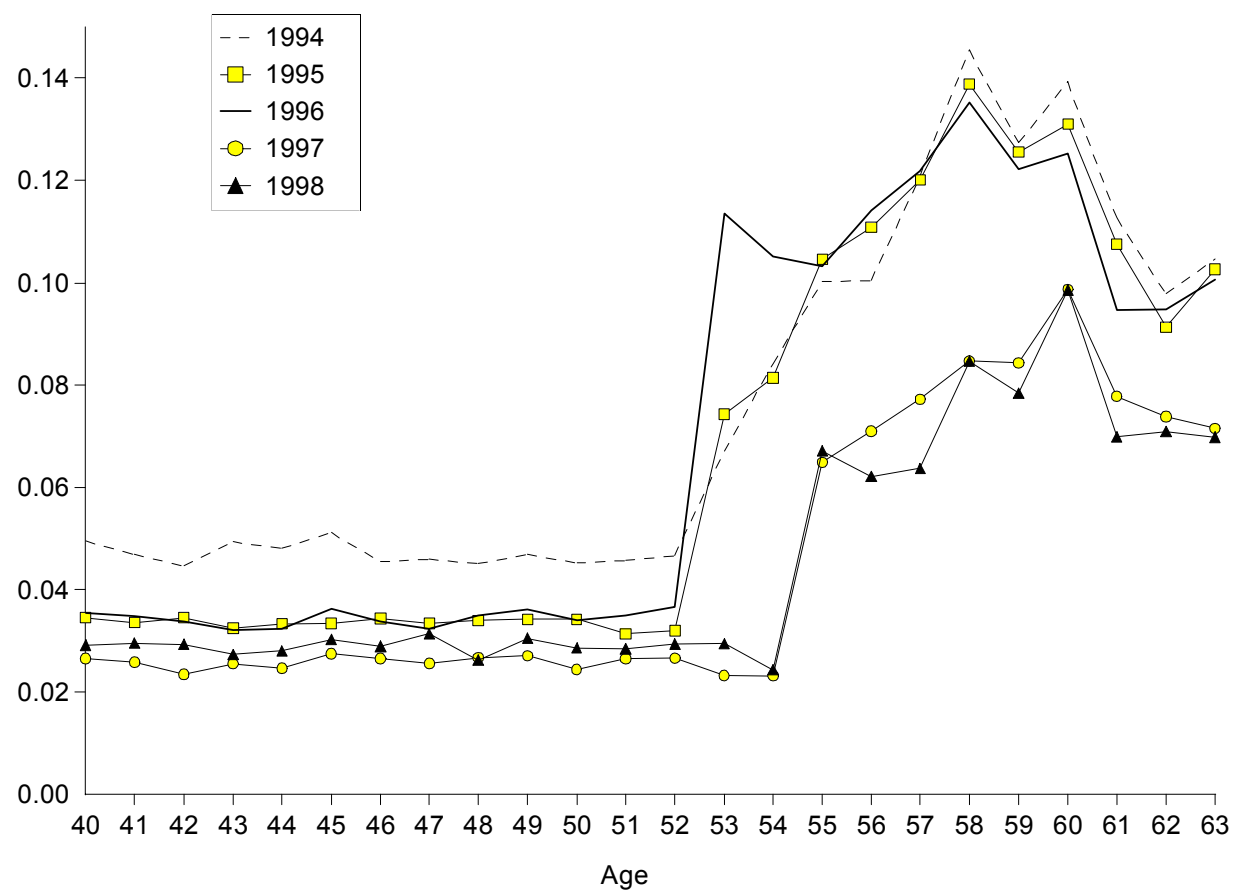

with a simple supply or demand side story alone. In most cases, unemployment causes, along with a social stigma, a notable cut in both gross and net income. Therefore, a claim that elderly workers are flowing into long-term unemployment of their own free will does not sound very convincing. Moreover, it seems economically irrational for employers to lay off disproportionate numbers of workers who have just passed the age limit of the UT scheme. Such workers yield a liability to the firm for the unemployment pension expenditure. The firm could easily avoid this liability by laying off employees that are a few years younger. In the case of a large firm (with more 500 employees), which aims to minimise the risk of disability pension expenditures, targeting dismissals at the elderly group of workers may have some economic reasoning but this does not explain why layoffs tend to fall on the elderly employees in firms of all sizes (see Rantala, 2002, for evidence of this).

One possibility is that the dismissals of older people, whose income levels are secured through the UT scheme or some other early retirement scheme, have an implicit approval from the general public and, to some extent, from the older people themselves. For example, some elderly people may agree to accept a lower income 
level in favour of much more leisure time. This view is formalised in a study by Hakola and Uusitalo (2001). Building on the work of Arnott et al. (1998) and Hutchens (1999), they lay out an optimal contract model of early retirement for Finland. In their model the dismissals of elderly employees are determined via an optimization problem where both the employer and employee are involved. An optimal contract specifies wages, firing rules, and severance payments so as to maximise the sum of expected utilities of the employer and worker. Within this framework a partially experience-rated unemployment pension system effectively subsides the dismissals of the elderly employees. This encourages firms to target dismissals at their older employees, which subsequently increases early retirement. In other words, if the firm cares about the welfare of its employees, it organises workforce reductions so that losses to the employees are minimised, which means that those who are eligible for the UT scheme are displaced in the first place. Hakola and Uusitalo also show that a number of predictions of their theoretical model are in accordance in empirical regularities observed in the Finnish micro data.

\subsection{The sample of the elderly unemployed}

In the subsequent analysis of unemployment durations we focus on workers between the ages of 50 and 57 who lost their private-sector job and became unemployed in 1996 or 1997, being continuously employed for at least two calendar years prior to the year of job loss. This group is eligible for unemployment benefits, and those old enough are also eligible for the UT scheme. Among those who became unemployed in 1996, all workers aged 53 and over at the beginning of the unemployment spell were eligible for the UT scheme. This age threshold was increased by two years at the beginning of 1997, so that the workers aged 53-54 were affected by the pension reform in 1997. The younger workers were not eligible for the UT scheme in either year, while the UT scheme was available for those aged 55 and over in both years.

For each worker in the data we observe the length of the unemployment spell (in days), exit destination, and a set of control variables. All unemployment spells that continue beyond the end of 2000 are recorded as censored. Sample statistics by age group are shown in Table 1 . The average duration of unemployment spells is close to one year for the youngest age groups, and even much longer for the two older groups. But when we look only at the completed spells, i.e. those eventually ending in employment, differences between the groups almost vanish. This may indicate that a large fraction of the two older age groups is not searching for a new job but instead is passively waiting for access to retirement. There is no strong 
Table 1: Sample statistics by age

\begin{tabular}{lccc}
\hline \hline & \multicolumn{3}{c}{ Age group } \\
\cline { 2 - 4 } & $50-52$ & $53-54$ & $55-57$ \\
\hline Unemployment duration, in days & $300(340)$ & $923(668)$ & $938(498)$ \\
Duration, completed spells & $160(198)$ & $172(211)$ & $156(198)$ \\
Married & .680 & .712 & .722 \\
Female & .502 & .534 & .520 \\
Dependent child & .222 & .121 & .075 \\
Swedish-speaking & .050 & .047 & .053 \\
Occupation: & & & \\
Commercial work & .168 & .140 & .138 \\
Technical & .075 & .073 & .070 \\
Teacher, lawyer, humanist & .024 & .021 & .021 \\
$\quad$ Health care & .016 & .012 & .009 \\
Clerical work & .219 & .249 & .200 \\
Forest work, farming, fishing & .020 & .012 & .017 \\
Transportation & .067 & .091 & .084 \\
Industrial work & .308 & .321 & .371 \\
Service work & .095 & .074 & .084 \\
$\quad$ Not classified & .008 & .007 & .005 \\
Education: & & & \\
$\quad$ Lower secondary & .301 & .253 & .240 \\
Upper secondary & .133 & .132 & .105 \\
Undergraduate or higher & .074 & .057 & .042 \\
Full experience & .920 & .954 & .968 \\
Unemployed in early 1990s & .377 & .286 & .323 \\
Past recall in early 1990s & .094 & .049 & .045 \\
Disabled & .036 & .036 & .030 \\
Unemployment started in winter time & .551 & .629 & .552 \\
Unemployment benefit, euro/day & $40.05(176)$ & $41.16(188)$ & $32.39(114)$ \\
log Unemployment benefit & $2.96(1.17)$ & $3.19(0.91)$ & $3.20(0.74)$ \\
Number of observations & 3,729 & 3,295 & 5,498 \\
\hline \hline
\end{tabular}

Notes: Sample standard deviations in parentheses. 
Table 2: Destination state by year and age, percent

\begin{tabular}{lrrrrrrr}
\hline \hline & \multicolumn{3}{c}{1996} & & \multicolumn{3}{c}{1997} \\
\cline { 2 - 4 } \cline { 7 - 8 } Exit destination & $50-52$ & $53-54$ & $55-57$ & & $50-52$ & $53-54$ & $55-57$ \\
\hline Employment & 50.5 & 17.4 & 13.3 & & 55.1 & 58.2 & 15.2 \\
ALMP programme & 31.6 & 9.7 & 2.7 & & 29.1 & 23.3 & 3.6 \\
Retirement & 0.4 & 0.5 & 52.4 & & 0.2 & 0.5 & 31.3 \\
Outside labour force & 13.4 & 15.4 & 13.8 & & 11.4 & 12.8 & 13.0 \\
Censored & 4.1 & 57.0 & 17.8 & & 4.2 & 5.2 & 36.9 \\
\hline \hline
\end{tabular}

seasonal variation in the timing of unemployment periods, as roughly one-half of unemployment spells started in the winter time, i.e. between October and March.

Given the age structure of our sample, it is not surprising to find that most of the individuals are married, nor that only a small share have a dependent child in the family. Some 5 percent of the unemployed in the data speak Swedish as their native language, which is slightly less than their proportion in the whole Finnish population. Not surprisingly, the elderly unemployed are rather poorly educated on average. Less than one-half in each group have obtained a formal educational degree after the compulsory comprehensive school. Frequency of educational degrees decreases with age. Commercial, clerical, and industrial jobs are the most typical occupations among the elderly unemployed. Almost all workers in the sample are fully experienced in their occupation according to the assessment of the employment authorities.

Less than 4 percent in each age group suffer from a reduced capacity for work owing to either mental or physical reasons. Roughly one-third were previously unemployed in the 1990s. This is a rather large fraction despite the fact that the early 1990s was a time of record high unemployment. Over 9 percent in the youngest group and below 5 percent in the older groups have experienced a temporary layoff period in the 1990s. There is no clear difference in the average levels of unemployment benefits received by the two younger age groups. The higher averages compared with the oldest group are due to few large observations (Q3 of the unemployment benefits is 32 euro per day in all three age groups).

Table 2 reports the distribution of post-unemployment destination states by age group and sampling year. The unemployed in the youngest group typically exit to employment or ALMP programmes. By contrast, workers between the ages of 55 and 57 rarely find a new job, and they do not participate in the ALMP programmes. In the case of this group, when the destination state is observed, it is most likely to be retirement. A high degree of censoring further implies that many retirements 
occur after the end of the observation period. The distribution of destination states for the age group 53-54 in 1997 closely resembles that for the age group 50-52. However, in the 1996 sample over one-half of the unemployment spells of workers aged 53-54 had not terminated by the end of 2000. This indicates very long periods of unemployment for this group prior to the increase in the age threshold of the UT scheme.

\section{Econometric Analysis}

The descriptive analysis above gives some clues as to how the UT reform in 1997 affected the unemployment experiences of older age groups. Keeping these lessons in mind, we lay out the following strategy for the econometric analysis:

1. After the reform in 1997 the inflow of elderly people to unemployment changed significantly. In quantifying this change we have to be aware of two effects: a shift in the age at which older workers enter unemployment and a change in the overall incidence of unemployment among the elderly. Here we need to account for the possible anticipation effects of the reform.

2. In the unemployment duration analysis we evaluate the extent to which exit behaviour to employment of the group affected by the reform, i.e. those aged 53-54 at the time of job loss, changed from 1996 to 1997. Additionally, we try to identify whether the behaviour of this group differs significantly from the behaviour of the younger group aged 50-52 after the reform. The duration analysis is done with three different methods: Kaplan-Meier, Cox proportional hazard, and quantile regressions. With all methods we allow for a flexible specification of the treatment effect such that it can vary over the quantiles of the unemployment duration distribution.

3. Having shown that the decline in the incidence of unemployment until retirement for 53-year-old employees and the sharp increase in the probability of re-employment for the unemployed aged 53-54 are attributable to the UT reform, we compute an expected change in unemployment benefits in the private sector resulting from the UT reform.

\subsection{Inflow from employment to unemployment}

As already outlined in Section 4, the risk of unemployment for the elderly employed changed sharply after the reform. We found that the risk function in age was shifted 
by two years to the right after the reform. The magnitude of this risk perhaps decreased for workers aged 55 and more as well. The first observation is easy to explain and it is an immediate consequence of the reform. The decrease in the inflow to unemployment among the older groups, which were not directly affected by the reform, needs more discussion. It can be due to changes in the business cycle or the anticipation behaviour of employers and older employees.

Anticipation effects just before the reform may lead to a higher risk of unemployment before and a lower risk after the reform. Note that workers aged 53 in 1996 will not be eligible for the UT scheme in the next year (but will be again in 1998) because of the increase in the age threshold. For this reason the curve of 1996 might be upward shifted for this group, which would simultaneously imply a downward shift of the 1997 curve for 54-year-old workers. The spike in the risk function at the age of 53 in 1996 in Figure 1 is consistent with the anticipation hypothesis, but there is no clear decline in 1997. Even in the absence of anticipation behaviour, we would expect unemployment risks among workers aged 54 and over to be lower in 1997 than in 1998, due to better macroeconomic conditions. This is not the case, however. Compared with 1998, the inflow rate in 1997 is lower for younger groups but higher for older groups. At this point it should be pointed out that the lower age limit for part-time pensions was reduced from 58 to 56 in 1998. If employers view part-time pensions as an alternative way of adjusting employment in the case of older employees, this reform may partly explain the decline in unemployment risks among the older groups in 1998.

To elaborate these issues further, we compute the cumulative risk of unemployment for 53-year-old individuals who were employed over the past two years, until they reach the age of $S$. This is defined for a given year $t$ as

$$
\operatorname{Pr}\left(U_{t, S} \mid E_{t, 51}, E_{t, 52}\right)=1-\prod_{k=53}^{S}\left[1-\operatorname{Pr}\left(U_{t, k} \mid E_{t, k-1}, E_{t, k-2}\right)\right],
$$

where $\operatorname{Pr}\left(U_{t, k} \mid E_{t, k-1}, E_{t, k-2}\right)$ is the probability of becoming unemployed at age $k$ conditional on being employed at the ages of $k-1$ and $k-2$, and thereby equals the curve of year $t$ in Figure 1. The cumulative risk and its change over a pair of years $t$ and $h$,

$$
\operatorname{Pr}\left(U_{h, S} \mid E_{h, k-1}, E_{h, k-2}\right)-\operatorname{Pr}\left(U_{t, S} \mid E_{t, k-1}, E_{t, k-2}\right),
$$

are depicted in Figures 2a and 2c respectively. As already mentioned, anticipation of the reform may upward bias the reform effect between the years 1996 and 1997. For 
Figure 2: Cumulative risk of unemployment
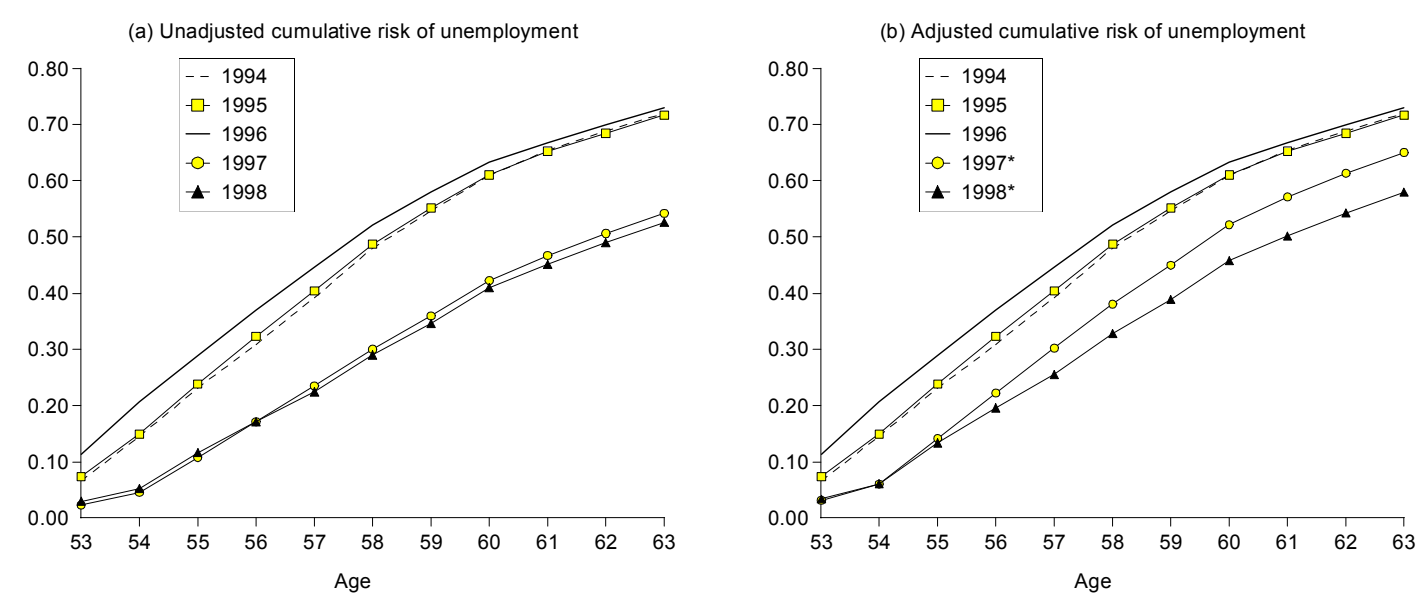

(c) Differences in unadjusted cumulative risks

(d) Differences in adjusted cumulative risks
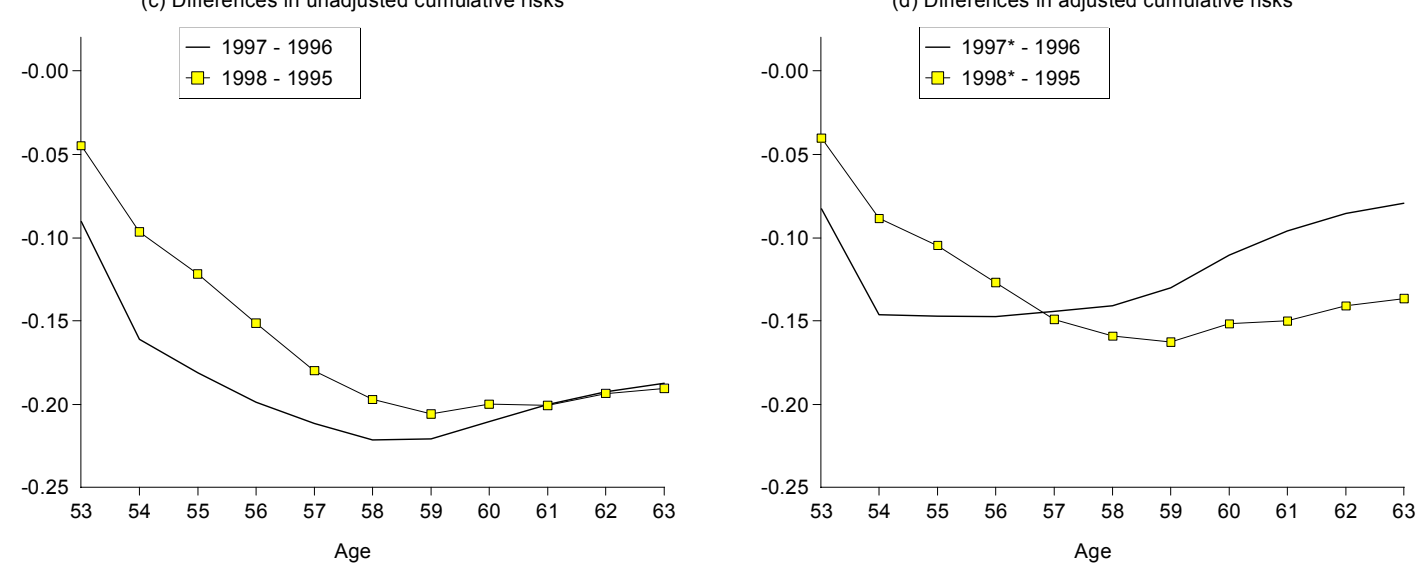

this reason, a comparison of 1995 and 1998 is a more legitimate and anticipation-free alternative, though it has to be done with the risk that the business cycle and the change in part-time pension rules more likely affect the results. In Figures $2 \mathrm{~b}$ and 2d the curves of 1997 and 1998 are adjusted for changes in the business cycle, using the younger workers as controls: the 1997 (1998) curve is made comparable to 1996 (1995). ${ }^{10}$

It is evident that there is a sharp decrease in the overall likelihood of becoming unemployed after the reform. The unadjusted decrease at the age of 63 is close to 20 percentage points between 1997 and 1996 as well as between 1998 and 1995. When

\footnotetext{
${ }^{10}$ Before computing the cumulative risks for $1997, \operatorname{Pr}\left(U_{97, k} \mid E_{97, k-1}, E_{97, k-2}\right)$ for $k=$ $53,54, \ldots, 63$ were rescaled with the ratio of the means of $\operatorname{Pr}\left(U_{97, k} \mid E_{97, k-1}, E_{97, k-2}\right)$ and $\operatorname{Pr}\left(U_{96, k} \mid E_{96, k-1}, E_{96, k-2}\right)$ over $k=40, \ldots, 52$. The unemployment risks for older workers in 1998 were similarly rescaled with the ratio of the mean probabilities over younger groups in 1998 and 1995. The underlying assumption is that the business cycle has the same proportional effect on the layoff risk in all groups between the ages of 40 and 63 .
} 
we control for the macro effects, we find smaller but still notable decreases (Figure $2 \mathrm{~d}$ ). The results do not indicate strong anticipation behaviour before the reform, since the difference at the age of 63 is either equal or smaller between 1998 and 1995 compared with the difference between 1997 and 1996 (Figures 2c and 2d).

Much of the decrease in the overall incidence of unemployment can be attributed to the reduced unemployment risk at the ages of 53 and 54 . If we compare the curves of 1994-1996 with the 1997 curve in Figure 2b, it seems that this is the only effect once we have eliminated the role of the business cycle. The curve of 1998 does not fit the story, however. It points to additional declines in the unemployment risk for those aged 55 and over. While this phenomenon remains a puzzle, reasons like increased use of part-time pensions, social pressure, or long-term changing labour market situations may play a role here.

\subsection{Unemployment duration analysis}

In this section we aim to quantify the effect of the UT reform on the length of unemployment spells until re-employment among the group affected by the reform. We define workers aged 53-54 who became unemployed in 1996 as the treatment group because their behaviour is expected to be affected by eligibility for the unemployment tunnel scheme. Since there are no untreated workers aged 53-54 in 1996, we do not observe the natural comparison group. Thus, we use workers aged 53-54 who became unemployed in 1997 as the comparison group. According to Doksum (1974), we define the treatment effect as the horizontal difference between the marginal distributions of unemployment durations between the treatment and comparison groups. Let $G(t \mid x)$ and $F(t \mid x)$ be the distribution functions conditional on observable characteristics $x$ for the treatment group and comparison group respectively. The conditional quantile treatment effect is then given by

$$
\delta(\tau \mid x)=G^{-1}(\tau \mid x)-F^{-1}(\tau \mid x)
$$

for the quantile $\tau \in[0,1]$, with $G^{-1}=\inf \{t \mid G(t \mid x) \geq \tau\}$ and $F^{-1}$ analogously. In other words, $\delta(\tau \mid x)$ equals the difference in the durations by which the fraction $\tau$ of the treatment group and the comparison group with characteristics $x$ have left unemployment for employment. For example, $\delta(.5 \mid x)$ gives the difference in the median durations between the groups.

Because our treatment and comparison groups are sampled at different points of time, the treatment effect is potentially sensitive to variation in the macroeconomic environment. For this reason we define the age groups 50-52 and 55-57 as the 
control groups that we will use to identify calendar time effects in the differencein-differences type setting. The younger group is supposed to be very similar to the comparison group, and the older group similar to the treatment group. The shape of the duration distributions is allowed to vary freely across the age groups and sampling years, as we wish to keep our treatment design flexible.

We specify three different econometric models for the estimation of the duration distributions. In particular, we focus on two classical approaches to duration analysis, namely the Kaplan-Meier estimator and a stratified data specification of competing risks Cox proportional hazard model. Moreover, we apply a recently emerging method based on quantile regressions (e.g. Koenker and Geling, 2001, Koenker and Bilias, 2001 and Koenker and Xiao, 2002).

\subsubsection{The Kaplan-Meier estimation}

In this approach the marginal distribution of durations for the treatment, comparison, and control groups are estimated in a nonparametric way when there is random censoring in the data; see Kaplan and Meier (1958). All durations are marked censored if the exit to employment is not observed. The Kaplan-Meier estimator is consistent for a wide class of distributions, since it is nonparametric. We use this approach as a reference model for further analysis. The main drawback of this method is the lack of robustness of the nonparametric estimates against compositional differences in the different groups.

Figure 3 shows survivor function estimates by age group and year. In Figure 3c we have added the 95\% confidence bands for the age groups 53-54 (solid lines) and 50-52 (shaded area) in 1997. The results indicate that we can expect a strong effect due to the reform. The survivor curve for the exit to employment for workers aged 53-54 drops sharply after the reform. The probability of remaining in unemployment after four years (i.e. 48 months) reduces from 80 to 30 percent after the reform. Note that the confidence bands for the age groups 53-54 and 50-52 in 1997 overlap, i.e. there are no statistically significant differences between these groups after the UT reform. This strongly suggests that the sharp difference in the survivor functions between these groups in 1996 was due to the age group 53-54's eligibility for the UT scheme. There is also evidence that the effect of the reform increases over the quantiles of the marginal duration distributions since the horizontal distance between the two predicted survivor functions for the age group 53-54 also does. 
Figure 3: Kaplan-Meier survivor function estimates
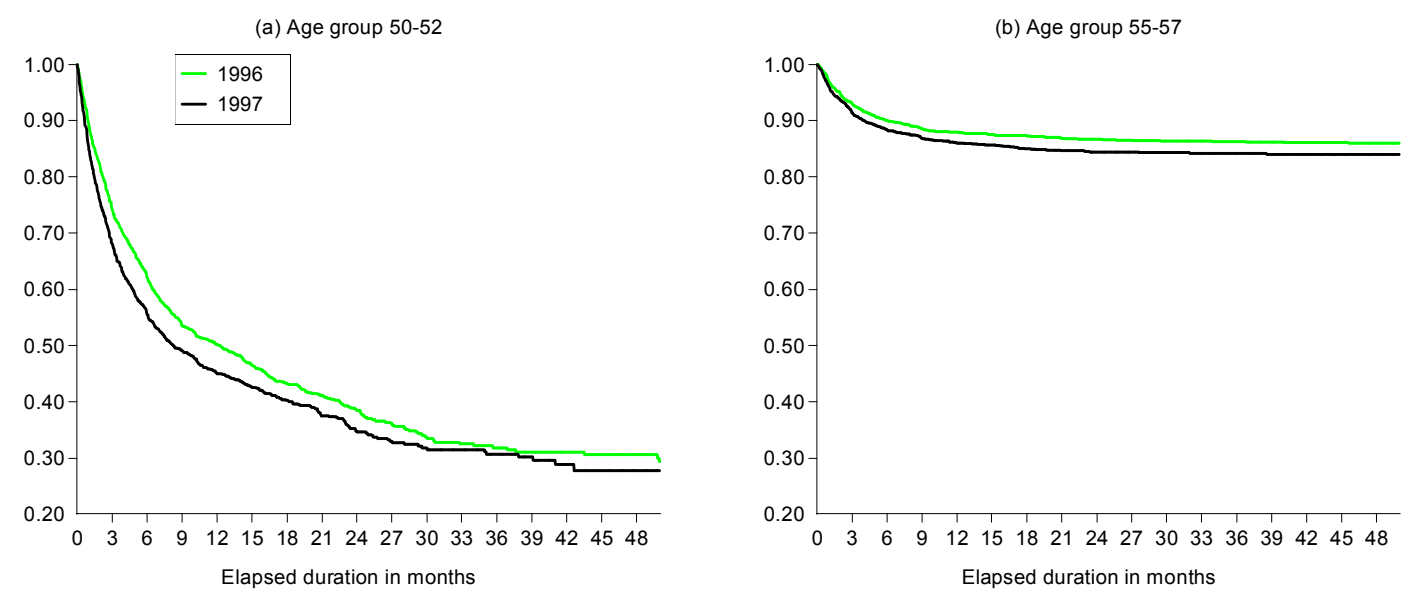

(c) Age group 53-54

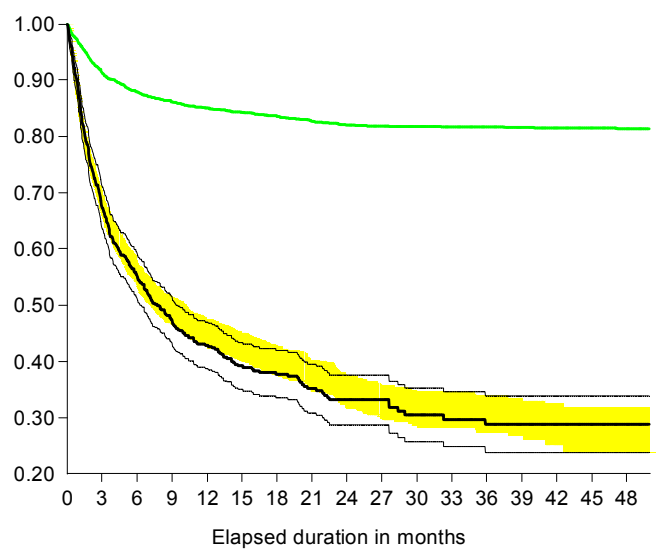

\subsubsection{The Cox proportional hazard model}

In our second approach to estimation we use a competing risks proportional hazard model. We now distinguish between independent exits from unemployment to employment, to ALMP programmes, to retirement and to out of the labour force. Censoring can therefore only occur at the end of the observation period. We consider the following stratified data version of the hazard rate of leaving unemployment to destination $j$ :

$$
\lambda_{j}^{k}(t \mid x)=\lambda_{0 j}^{k}(t) \exp \left(x^{\prime} \beta_{j}\right),
$$

where $k$ refers to a given age group $(50-52,53-54$, or 55-57) in the sampling year 1996 or 1997. We use Cox's (1972) partial likelihood method to estimate $\beta_{j}$, where we do not have to specify the baseline hazards $\lambda_{0}$. However, in the second stage the baseline hazards are estimated nonparametrically using the product limit estimator 
given in Kalbfleisch and Prentice (1980). ${ }^{11}$

It is worth emphasizing that we leave the destination-specific baseline hazard flexible over the years and over the age groups. This implies a flexible treatment design where the treatment effect is captured by the baseline hazards, which are nonparametric and specific to each group. Stated differently, the shape of the unemployment duration distribution until exit to employment is allowed to vary freely across the treatment, comparison, and control groups, and thereby no restrictions on the variation of the treatment effect over the quantiles is imposed. By contrast, the effects of control variables $x$ are modelled in a parametric way, i.e. the familiar proportional effect on the underlying baseline hazard is assumed.

The Cox PH model allows analysing to see whether the Kaplan-Meier estimates are affected by sorting over the duration time with respect to the observed regressors. The model does not allow for unobserved heterogeneity, however. Estimation results may therefore be affected by sorting with respect to unobservables. If so, we do not obtain consistent estimates of the baseline hazard, and the parameter estimates $\beta_{j}$ may be biased as well. There is, however, evidence that unobserved heterogeneity may be a less serious problem when flexible baseline hazards are used. It is likely to be more of a problem of parametric models that assume a particular parametric form for the baseline hazard. A number of studies have found that incorporating unobserved heterogeneity into semiparametric duration models has only a minor effect on the results (e.g. Meyer, 1990, and Han and Hausman, 1990). In any case, we estimate two specifications in order to make our results more robust with respect to possible effects due to unobserved heterogeneity. We chose one basic model with the classical, directly observable variables, and one specification including variables computed from the working history of the unemployed. These variables capture to some extent the specific behaviour of the unemployed (Lüdemann et al., 2004). They should therefore reduce the magnitude of unobserved heterogeneity.

Figure 4 shows the Cox survivor function estimates evaluated at the sample means of the regressors. The estimated coefficients are presented in Table 5 in the Appendix. It is evident that there are no big differences compared with the KaplanMeier survivor functions. By virtue of the overlapping $95 \%$ confidence bands in Figures $4 \mathrm{e}$ and $4 \mathrm{f}$, we come to the same conclusion that the exit behaviour of the age group 53-54 does not differ significantly from the behaviour of the age group 5052 after the reform. It seems therefore that the Kaplan-Meier survivor functions are not strongly affected by sorting over the duration time with respect to the observed

\footnotetext{
${ }^{11}$ For this purpose we apply the SAS procedure PHREG.
} 
Figure 4: Cox survivor function estimates for exits to employment, evaluated at the sample means
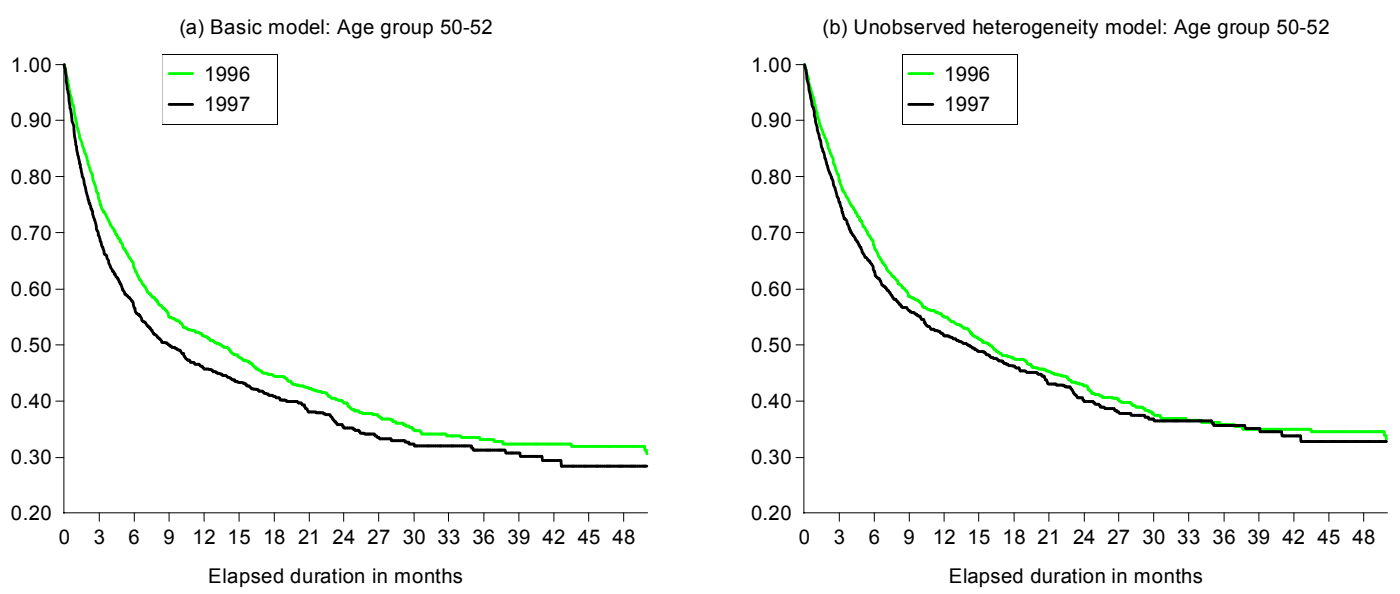

(c) Basic model: Age group 55-57

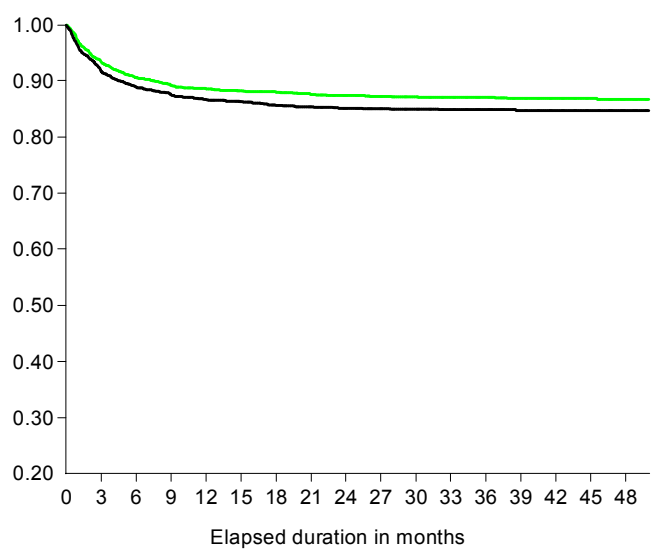

(d) Unobserved heterogeneity model: Age group 55-57

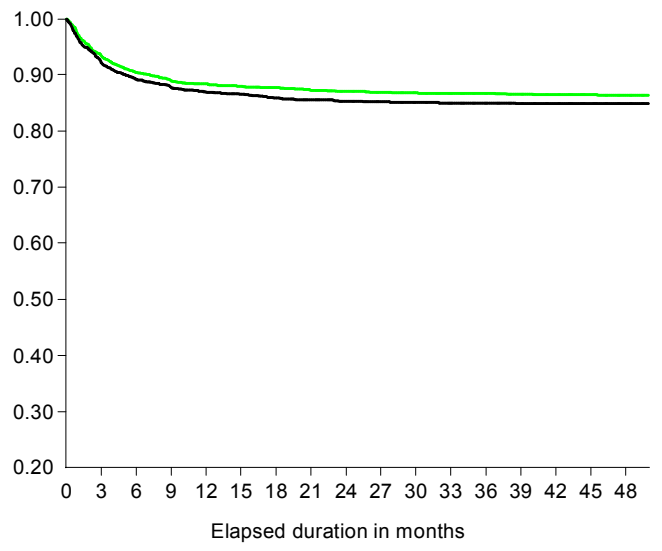

(e) Basic model: Age group 53-54

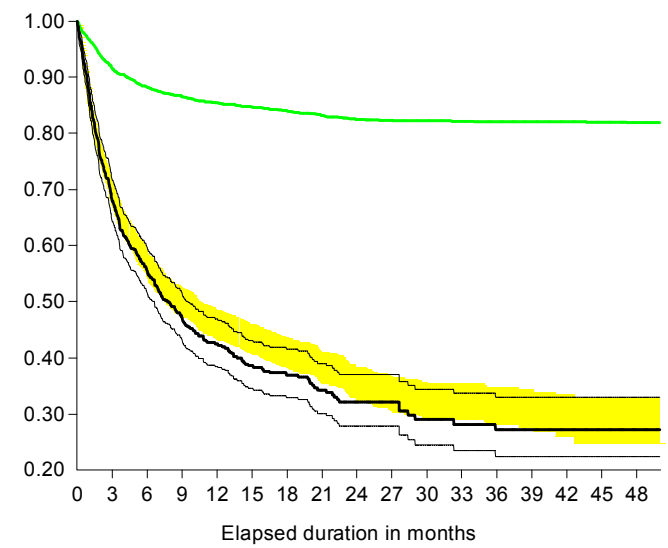

(f) Unobserved heterogeneity model: Age group 53-54

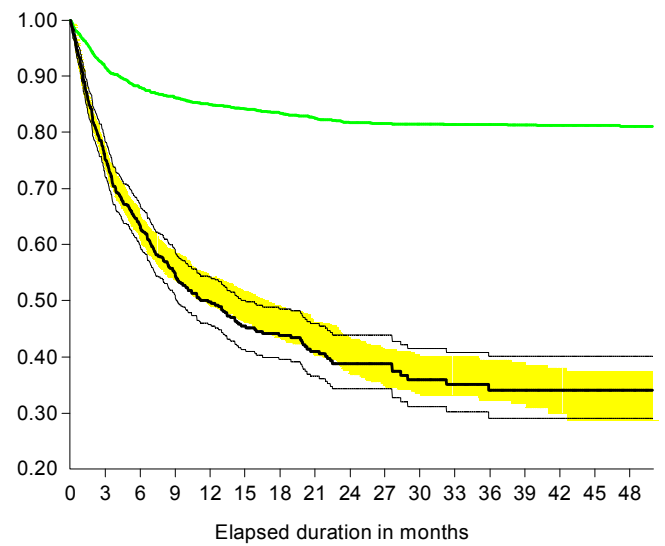


regressors and with respect to the individuals' work history information.

It should be noted that the degree of censoring within the groups eligible for the UT scheme is very high. The survivor functions of these groups decrease over the first 24 months but remain above the level of .80 until the end of the observation period. This suggests the possibility that a notable fraction of the unemployed who are eligible for the UT scheme are not even looking for a new job but are passively waiting for early retirement. If so, the transition rate to employment for such workers is zero, and thereby the proportional hazard assumption is violated. ${ }^{12}$ It is not clear how robust our results are with respect to this sort of unobserved heterogeneity. In order to check the robustness of our results, we turn to quantile regressions that allow for a more flexible specification for the effects of the regressors.

\subsubsection{Quantile regressions}

This model allows for a variety of effects from the regressors on the distribution of unemployment durations. Consider the following relationship of the log duration on some regressor vector $x$ and an error term $u$ with distribution function $F_{u}$ :

$$
\log (T)=\beta^{\prime} x+\left(x^{\prime} \gamma\right) u
$$

This class of models belongs to the linear scale-location models which imply the following conditional quantile function of the $\log$ durations for quantile $\tau$ :

$$
Q_{\log (T)}(\tau \mid x)=x^{\prime} \beta+x^{\prime} \gamma F_{u}^{-1}(\tau)=x^{\prime} \beta(\tau),
$$

with $\beta(\tau)=\beta+\gamma F_{u}^{-1}(\tau)$, see Koenker and Geling (2001). The coefficients therefore depend on the quantile $\tau$. The model reduces to the accelerated failure time model, if one imposes $x^{\prime} \gamma=1$. If, in addition, the error term $u$ follows an extreme value distribution, we obtain the Weibull proportional hazard model. In both cases the coefficients $\beta$ do not depend on the quantile of the distribution of $\log (T)$, which is rather restrictive. The same restriction is imposed by the Cox $\mathrm{PH}$ model for a different transformation of the duration variable (i.e. $\log (T)$ replaced with the integrated baseline hazard). A common feature of these traditional duration models is that the covariates $x$ affect only the location of the distribution of the transformed duration variable, without affecting its shape. Using the quantile regression models, we can allow the covariates $x$ to affect both the location and shape of the duration distribution. The linear scale-location model above is a special case where all components

\footnotetext{
${ }^{12}$ In this case the distribution of unemployment durations until exit to employment is defective in the sense that it does not converge to one even when the duration time approaches infinity.
} 
of $\beta(\tau)$ depend on $\tau$ in the same way. We do not impose such a restriction but allow for a more general form of heterogeneity below.

For the estimation of the conditional quantile treatment effect, we use a specification which has the same difference-in-differences type meaning that has enjoyed widespread popularity in the linear model setting. Hunt (1995) and Carling et al. (2001) exploit this methodology in the context of the proportional hazard models when analysing unemployment compensation reforms in Germany and Sweden respectively. We include a year dummy for 1997, group dummies for workers aged 53-54 and 55-57, and an interaction term for the age group 53-54 in 1997, along with other covariates $x$ as the explanatory variables for the quantile regression model for log durations. The reference group is workers aged 50-52 in 1996. In terms of log durations the quantile treatment effect is directly related to the estimated coefficient for the interaction term (say $\beta_{5354,97}$ ), which captures the change in exit behaviour of the age group affected by the UT reform beyond the business cycle effect. The business cycle effect, measured by the coefficient of the year dummy, is identified from the change in the exit behaviour of the control groups, i.e. age groups 50-52 and 55-57, from 1996 to 1997. Assuming that the effect of the business cycle is the same for all age groups, the interaction term coefficient identifies the treatment effect, i.e. the effect of the UT reform on the age group 53-54. Given the log transformation of durations, the conditional treatment effect for quantile $\tau$ can be computed by

$$
\hat{\delta}(\tau \mid x)=\exp \left[\hat{\beta}_{0}(\tau)+\hat{\beta}_{5354}(\tau)+\hat{\beta}^{\prime} x\right]-\exp \left[\hat{\beta}_{0}(\tau)+\hat{\beta}_{5354}(\tau)+\hat{\beta}_{5354,97}(\tau)+\hat{\beta}^{\prime} x\right]
$$

where $\hat{\beta}_{0}$ is the estimated intercept, $\hat{\beta}_{5354}$ is the estimated coefficient for the age group 53-54, and $x$ is the vector of all other regressors with corresponding coefficients $\hat{\beta}$. The first term on the right-hand side corresponds to $G^{-1}(\tau \mid x)$, the predicted quantile for the treatment group of workers aged 53-54 in 1996 under the pre-reform regime. The second term is an estimate of $F^{-1}(\tau \mid x)$, the predicted quantile for the comparison group, which is now the age group 53-54 in 1996 under the postreform regime. In the application we will compute $\hat{\delta}(\tau \mid x)$ at the sample means of the covariates $x$.

For the estimations we use the durations $T$, which are non-censored if the exit of an individual to employment is observed; otherwise they are marked as censored (exit to other states or end of observation period). ${ }^{13}$ We use the algorithm of Fitzenberger (1997), which is implemented in the most recent version of TSP 4.5. Due to a certain amount of censoring at the end of the data we cannot expect reliable results for the

\footnotetext{
${ }^{13}$ In fact, we are estimating the quantiles of a defective distribution with censored data.
} 
Figure 5: QR estimates of treatment group coefficients from the basic model (left panel) and from the unobserved heterogeneity model (right panel)
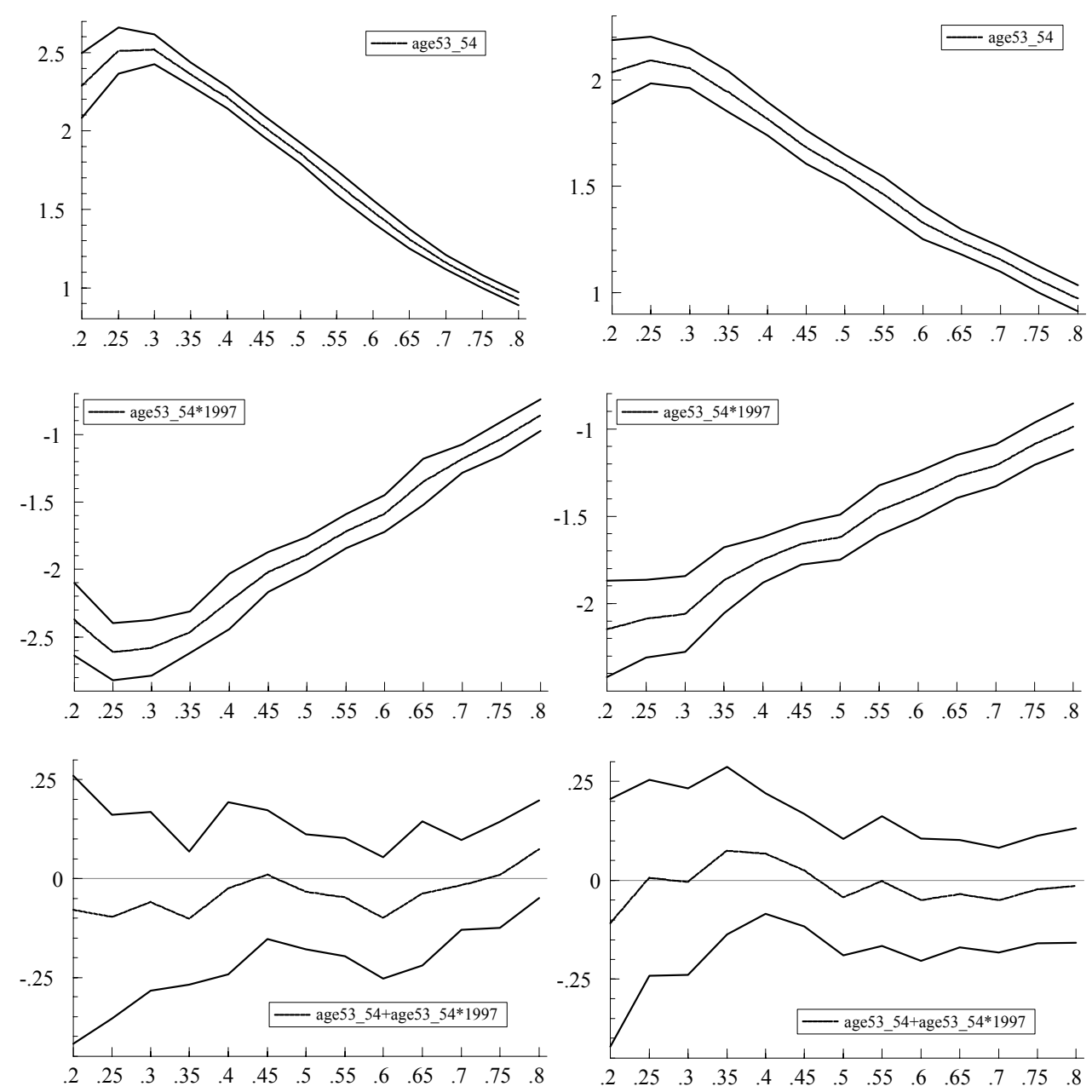

upper quantiles. In general, it may happen that the quantile treatment effect is not identifiable for some quantiles because they are not observed in real world data. This is the case in clinical studies if the treated individuals survive the observation period, but many of the untreated do not. This may occur in the unemployment duration analysis if a large fraction of the unemployed in the treatment group do not exit to employment because they retire or drop out of the labour market. Therefore some upper quantiles of the distribution may become unobservable. In general, the treatment effect is only identifiable for $\tau \in[0, \bar{\tau}]$ with $\bar{\tau}=\min \left\{G_{n_{1}}(\bar{T}), F_{n_{0}}(\bar{T})\right\}$ and $\bar{T}$ is the end of the observation period.

We again estimate two models: one basic specification and one specification in- 
Table 3: Quantile treatment effects in months

\begin{tabular}{cccccccc}
\hline \hline Quantile & \multicolumn{3}{c}{ Basic model } & & \multicolumn{3}{c}{ Unobs. heterogeneity } \\
\cline { 2 - 3 } \cline { 6 - 7 }$\tau$ & $G^{-1}(\tau \mid \bar{x})$ & $F^{-1}(\tau \mid \bar{x})$ & $\delta(\tau \mid \bar{x})$ & & $G^{-1}(\tau \mid \bar{x})$ & $F^{-1}(\tau \mid \bar{x})$ & $\delta(\tau \mid \bar{x})$ \\
\hline .20 & 23.7 & 2.2 & 21.5 & & 22.2 & 2.6 & 19.6 \\
.25 & 37.2 & 2.7 & 34.4 & & 30.9 & 3.8 & 27.0 \\
.30 & 44.9 & 3.4 & 41.5 & & 36.5 & 4.7 & 31.9 \\
.35 & 49.4 & 4.2 & 45.2 & & 40.9 & 6.3 & 34.6 \\
.40 & 51.3 & 5.5 & 45.9 & & 43.5 & 7.6 & 35.9 \\
.45 & 52.5 & 7.0 & 45.5 & & 45.7 & 8.7 & 37.0 \\
.50 & & 8.1 & & & 47.8 & 9.5 & 38.4 \\
.55 & 9.9 & & 50.0 & 11.6 & 38.5 \\
.60 & 11.4 & & 52.3 & 13.2 & 39.1 \\
\hline \hline
\end{tabular}

Notes: Predicted quantiles are evaluated at the sample means of the regressors x. We do not report quantiles exceeding 52.6 months, which is the average length of the observation period for workers aged 53-54 who became unemployed in 1996.

cluding variables depending on the previous employment and unemployment history of the unemployed. Figure 5 displays the estimated coefficients along with the $90 \%$ bootstrapping confidence bands for the age group 53-54 and the interaction term for various quantiles. The estimated coefficients for other variables are shown in Figures 6 and 7 in the Appendix. From Figure 5 it is apparent that the effect of the reform varies over the quantiles of the marginal distribution of unemployment durations (see the coefficient of the interaction term). We also observe that the sum of the two coefficients is not significantly different from zero, so that the age group 53-54 does not possess different exit behaviour from unemployment to employment after the reform in 1997 compared with the control group of workers aged 50-52. This is in line with the previous findings that the Kaplan-Meier and Cox survivor curves for these groups are basically the same after the reform.

The estimated quantile treatment effects are given in Table 3. As already mentioned, the systematic censoring at the end of the data does not allow us to consistently estimate the model for the upper quantiles. When we evaluate the predicted quantile functions at the sample means of the other regressors, we do not obtain reliable predictions for the treatment group (i.e. $G^{-1}$ ) for quantiles $\tau>.45$ in the basic model and for $\tau>.60$ in the unobserved heterogeneity model. The conditional quantile treatment effect is therefore not estimated above these limits. We find a strong positive treatment effect for all observed quantiles. The treatment effect increases over the lower end of the distribution, which indicates that the horizontal distance between the distribution functions of the treatment and 
comparison groups increases over the quantiles. This might be due to a large share of the unemployed in the treatment group who never leave for employment because of the unemployment pension option.

\subsection{Change in unemployment benefits}

In the light of our empirical findings, both the incidence and expected duration of unemployment depend on age and the age threshold for the UT scheme. We found that in terms of unemployment experiences workers aged 53-54 do not differ from those aged 50-52 after the reform in 1997. This suggests that the higher risk and longer average duration of unemployment for this group before the reform were only due to a single reason: eligibility for the UT scheme. In this section we quantify the reduction in unemployment benefits in the private sector attributable to the increase in the age threshold of the UT scheme.

Consider a 53-year-old worker who has been employed in the private sector over the past two years. We aim to determine the expected amount of unemployment benefits received by this worker until he or she transfers to the normal old-age pension. For simplicity, we neglect the possibility of multiple unemployment spells and focus on one potential spell of unemployment. This seems reasonable, as there is no evidence of the effect of the UT reform on the frequency of additional spells of unemployment. ${ }^{14}$ Under this assumption and conditional on being employed in the private sector between the ages of 50 and 51, the expected per capita amount of unemployment benefits is given by

$$
E(B)=\sum_{s=53}^{64} \operatorname{Pr}\left(U_{s}\right) E\left(B \mid U_{s}\right)
$$

where $\operatorname{Pr}\left(U_{s}\right)$ is the probability that the unemployment spell begins at age $s$, and $E\left(B \mid U_{s}\right)$ is the expected amount of unemployment benefits collected over the spell of unemployment that begins at age $s . E\left(B \mid U_{s}\right)$ can be recovered from unemployment duration and benefit data, whereas $\operatorname{Pr}\left(U_{53}\right)=\operatorname{Pr}\left(U_{53} \mid E_{52}, E_{51}\right)$ and for $s>53$,

$$
\operatorname{Pr}\left(U_{s}\right)=\operatorname{Pr}\left(U_{s} \mid E_{s-1}, E_{s-2}\right) \prod_{k=53}^{s-1}\left[1-\operatorname{Pr}\left(U_{k} \mid E_{k-1}, E_{k-2}\right)\right] .
$$

\footnotetext{
${ }^{14}$ Of workers aged 53-54 who became unemployed in 1996 but escaped to employment, the ALMP programme or outside the labour force, 68 percent had experienced an another spell of unemployment by the end of 1999. For the same age group in the 1997 sample, the corresponding share is 69 percent for the period ending in 2000.
} 
Note that $\operatorname{Pr}\left(U_{s}\right)$ is the change in the cumulative risk of unemployment defined in (1) from age $s-1$ to $s$, and therefore equals the slope of the curves in Figures 2a and $2 \mathrm{~b}$.

We wish to compute $E(B)$ under two regimes of the age threshold for the UT scheme: 53 (pre-reform regime) and 55 (post-reform regime). The difference in $E(B)$ between these regimes is

$$
\Delta E(B)=\sum_{s=53}^{64}\left[\operatorname{Pr}_{\text {post }}\left(U_{s}\right) E_{\text {post }}\left(B \mid U_{s}\right)-\operatorname{Pr}_{\text {pre }}\left(U_{s}\right) E_{\text {pre }}\left(B \mid U_{s}\right)\right] .
$$

In order to estimate this quantity, we make the following assumptions:

A1: $E_{\text {post }}\left(B \mid U_{s}\right)=E_{\text {pre }}\left(B \mid U_{s}\right)$ for $s=55,56, \ldots, 64$.

A2: $\operatorname{Pr}_{\text {post }}\left(U_{s}\right)=\operatorname{Pr}_{\text {pre }}\left(U_{s}\right)$ for $s=55,56, \ldots, 64$.

A3: $\operatorname{Pr}_{\text {post }}\left(U_{50} \mid E_{49}, E_{48}\right)=\operatorname{Pr}_{\text {post }}\left(U_{51} \mid E_{50}, E_{49}\right)=\ldots=\operatorname{Pr}_{\text {post }}\left(U_{54} \mid E_{53}, E_{52}\right)$.

A4: $E_{\text {post }}\left(B \mid U_{50}\right)=E_{\text {post }}\left(B \mid U_{51}\right)=\ldots=E_{\text {post }}\left(B \mid U_{54}\right)$.

Assumptions 1 and 2 say there are no spillover effects. Assumption 1 is a trivial one, as the UT reform in 1997 had no effect on the position of the unemployed aged 55 and over. Assumption 2 is less obvious and needs more discussion. In Figure 2a the pre-reform curves of 1994-1996 are more steeper than the post-reform curves of 1997 and 1998 over the whole age range. This observation is in clear contrast to Assumption 2. However, once we control for macro effects, the difference in the slopes after the age of 54 more or less disappears in the case of the 1997 curve (see Figure 2b) which is consistent with Assumption 2. However, the 1998 curve for older groups remains flatter than the curves of 1994-1996, which may be a result of the change in the part-time pension rules in 1998. Assumption 3 suggests that the risk of unemployment is constant between the ages of 50 and 54 under the post-reform regime. This can be verified from the 1997 and 1998 curves in Figure 1. According to Assumption 4, the expected amount of unemployment benefits under the postreform regime is the same for the unemployed between the ages of 50 and 54. This should be the case, as they share the same unemployment compensation rules after the reform and the post-reform distributions of unemployment durations were found to be identical for the age groups 50-52 and 53-54 in the duration analysis.

Under the assumptions above, the terms for $s=55,56, \ldots, 64$ cancel out in (4) and estimates only for two age groups are required. The pre-reform values of $\operatorname{Pr}\left(U_{53}\right)$ 
and $\operatorname{Pr}\left(U_{54}\right)$ are estimated through the use of the unemployment risks for workers aged 53-54 in 1996 as

$$
\begin{aligned}
& \widehat{\operatorname{Pr}_{\text {pre }}}\left(U_{53}\right)=\widehat{\operatorname{Pr}}\left(U_{96,53} \mid E_{96,52}, E_{96,51}\right), \\
& \widehat{\operatorname{Pr}_{\text {pre }}}\left(U_{54}\right)=\widehat{\operatorname{Pr}}\left(U_{96,54} \mid E_{96,53}, E_{96,52}\right)\left[1-\widehat{\operatorname{Pr}}\left(U_{96,53} \mid E_{96,52}, E_{96,51}\right)\right],
\end{aligned}
$$

where the probability terms on the right-hand side correspond to the values of the 1996 curve in Figure 1. The post-reform values are estimated through the use of the data on workers aged 50-52 in 1996 (Assumption 3) as

$$
\begin{aligned}
& \widehat{\operatorname{Pr}_{\text {post }}}\left(U_{53}\right)=\overline{\operatorname{Pr}}\left(U_{96,50-52} \mid E_{96,48-51}\right), \\
& \widehat{\operatorname{Pr}_{\text {post }}}\left(U_{54}\right)=\overline{\operatorname{Pr}}\left(U_{96,50-52} \mid E_{96,48-51}\right)\left[1-\overline{\operatorname{Pr}}\left(U_{96,50-52} \mid E_{96,48-51}\right)\right],
\end{aligned}
$$

where

$$
\overline{\operatorname{Pr}}\left(U_{96,50-52} \mid E_{96,48-51}\right)=\frac{1}{3} \sum_{s=50}^{52} \widehat{\operatorname{Pr}}\left(U_{96, s} \mid E_{96, s-1}, E_{96, s-2}\right) .
$$

However, the 1996 data are problematic in this case because the spike at the age of 53 points to anticipation behaviour. Therefore, we also use the unemployment risks in 1995 to estimate these probabilities.

We can estimate $E\left(B \mid U_{s}\right)$ for $s=53,54$ under the two regimes by taking the sample means of unemployment benefits received by appropriately chosen worker groups over their observed unemployment spells. ${ }^{15}$ The pre-reform estimates are obtained as

$$
\widehat{E}_{\text {pre }}\left(B \mid U_{53}\right)=\widehat{E}_{\text {pre }}\left(B \mid U_{54}\right)=\frac{1}{n} \sum_{i=1}^{n}\left(b_{i} t_{i}\right),
$$

where $b_{i}$ is the average unemployment benefit per day, and $t_{i}$ is the unemployment duration in days for the $i$ th worker in the age group 53-54 who became unemployed in 1996. For the post-reform estimates, we can exploit inflow data either on workers aged 50-52 in 1996 or workers aged 53-54 in 1997. The use of the younger group as a reference relies on Assumption 4. We prefer to use this group, as then we do not need to worry about the macro effects, which would be the case with the age group 53-54 in 1997. Thus, we use

$$
\widehat{E}_{\text {post }}\left(B \mid U_{53}\right)=\widehat{E}_{\text {post }}\left(B \mid U_{54}\right)=\frac{1}{m} \sum_{j=1}^{m}\left(b_{j} \min \left\{t_{j}, 730\right\}+b_{0} \max \left\{t_{j}-730,0\right\}\right),
$$

\footnotetext{
${ }^{15}$ Note that the mean unemployment duration is not directly observable because of the unemployment spells that have not terminated by the end of the observation period. To overcome this difficulty, we assume that such spells continue until the age of 60 , i.e that these workers will eventually end up with the unemployment pension. This seems reasonable, as the employment hazards were found to be very flat over the last 12 months of the observation period or so.
} 
Table 4: Expected change in unemployment benefits

\begin{tabular}{|c|c|c|}
\hline \multirow[b]{2}{*}{ Probability of job loss } & \multicolumn{2}{|c|}{ UT regime } \\
\hline & Pre-reform & Post-reform \\
\hline $\operatorname{Pr}\left(U_{53}\right)$ in 1995 & .0743 & .0325 \\
\hline $\operatorname{Pr}\left(U_{54}\right)$ in 1995 & .0753 & .0315 \\
\hline $\operatorname{Pr}\left(U_{53}\right)$ in 1996 & .1136 & .0351 \\
\hline $\operatorname{Pr}\left(U_{54}\right)$ in 1996 & .0932 & .0339 \\
\hline \multicolumn{3}{|c|}{ Expected amount of unemployment benefits } \\
\hline$E\left(B \mid U_{53}\right)=E\left(B \mid U_{54}\right)$ & 41,482 & 8,651 \\
\hline \multicolumn{3}{|c|}{ Change in expected unemployment benefits } \\
\hline$\Delta E(B)$ using 1995 probabilities & \multicolumn{2}{|c|}{$-5,652$} \\
\hline$\Delta E(B)$ using 1996 probabilities & \multicolumn{2}{|c|}{$-7,982$} \\
\hline \multicolumn{3}{|l|}{ Expected population change } \\
\hline$N \times \Delta E(B)$ using 1995 probabilities & \multicolumn{2}{|c|}{-88 million } \\
\hline$N \times \Delta E(B)$ using 1996 probabilities & \multicolumn{2}{|c|}{-125 million } \\
\hline
\end{tabular}

Note: $\mathrm{N}=15,620$ is the number of private-sector employees aged 53 in 1996 who has been continuously employed over the past two years. This number was estimated from the ES database.

where $b_{j}$ and $t_{j}$ refer to the $j$ th worker in the age group 50-52 who became unemployed in 1996. Here we assume that the worker loses his unemployment benefit $b_{j}$ after two years of unemployment and starts to collect the labour market support $b_{0}$ $(=14$ euro/day $)$.

Table 4 displays our estimates. We see that the expected per capita amount of unemployment benefits in the case of job loss was reduced from 41,500 to 8,700 euros owing to the reform. This sharp decrease results mainly from the shorter expected duration of unemployment after the reform. Substituting these figures along with the estimated probabilities into (4) gives the expected reduction in unemployment benefit for a 53-year-old employee in the private sector. This amounts to 5,700 or 8,000 euros depending on the year we use to estimate the probability terms. In order to obtain the expected population change, we simply multiply these quantities with the number of 53-year-old employees in the private sector. This gives the estimated decline in unemployment benefits received by this age cohort in the private sector. Using the probabilities from 1996 we find the UT reform led to a reduction of 125 million euros in unemployment benefits in the private sector for a single age cohort. Recall that the probability estimates for the pre-reform regime from 1996 are expected to be too high because of anticipation behaviour, which would bias our 
estimate of the unemployment benefit savings upwards. Therefore, using the 1995 data for the probability estimates may be a more appropriate choice. In doing so, the aggregate saving of the unemployment benefits of the age cohort is reduced to 88 million. In any case, the UT reform led to a considerable reduction in unemployment benefits in the private sector.

Under the constant macro-environment and equal-sized age cohorts, these numbers give the annual saving of the UT reform. In general, the actual saving for each age cohort depends on the size of the cohort and business cycle conditions they face until the age of 65 . Note also that our analysis does not take into account the (possible) indirect effects for the younger age groups and for the companies who may benefit from the early retirement of the elderly. Nor do we account for a reduction in the unemployment pension expenditures and likely increases in the other early retirement expenditures. Our analysis is therefore only a partial evaluation.

\section{Conclusion}

Beyond any doubt, disproportionate numbers of dismissals fall on the group of older workers who are eligible for the UT scheme. It seems that employers actively exploit the UT scheme to get rid of their elderly employees. This kind of a culture of early labour market withdrawal is in sharp contrast with the original idea of the experience-rating of early retirement schemes, which was to encourage employers to invest in working conditions and preventive measures to reduce the disability and layoff risks of their older employees.

In this paper we have analysed the effect of the two-year increase in the eligibility age of the unemployment tunnel scheme on the incidence and duration of unemployment among elderly workers. We found a large decrease in the inflow to unemployment and a large increase in the transition rate out of unemployment to employment owing to the UT reform. The treatment effect was found to vary over the different quantiles of the unemployment duration distribution, highlighting the importance of the flexible specification for the treatment effect. All the flexible estimation methods - namely, the Kaplan-Meier estimator, stratified Cox proportional hazard model, and quantile regression-produced robust and coherent results. It became evident that the probability of exiting unemployment to employment for the group affected did not significantly differ from the control group (i.e. 50-52 years old) after the reform. The high risk of unemployment and the low escape rates from unemployment in the treatment group before the reform were only due 
to the unemployment tunnel scheme and not because of a difficult labour market for elderly workers. We computed the expected saving in unemployment benefits in the private sector due to the reform and found that it was in the range of 100 million euros per age cohort. For these reasons, the UT reform in 1997 may be viewed as a success story. On the other hand, the poor employment prospects of elderly workers can be attributed to the Finnish social security system that encourages employers for age discrimination and older unemployed to withdraw from the labour market. Therefore, a more cynical observer may see the 1997 reform as a partial correction of the self-inflicted catastrophe rather than the success story. 


\section{References}

[1] Arnott, R. J., Hosios, A. J., and J. E. Stiglitz (1998), "Implicit contracts, labour mobility and unemployment", The American Economic Review, 78(5), 1046-1066.

[2] Carling, K., Holmlund, B., and A. Vejsiu (2001), "Do benefit cuts boost job finding? Swedish evidence from the 1990s", The Economic Journal, 111, 766790 .

[3] Cox, D. R. (1972), "Regression models and life tables (with discussion)", Journal of the Royal Statistical Society, B, 34, 187-220.

[4] Doksum, K. (1974), "Empirical probability plots and statistical inference for nonlinear models in the two-sample case", Annals of Statistics, 2, 267-277.

[5] Fitzenberger, B. (1997), "A guide to censored quantile regressions", in Handbook of Statistics: Robust Inference, eds. G.S. Maddala, and C. R. Rao, Vol. 15, North-Holland, Amsterdam, 235-287.

[6] Han, A., and J. A. Hausman (1990), "Flexible parametric estimation of duration and competing risk models", Journal of Applied Econometrics, 5, 1-28.

[7] Heckman, J., and B. Singer (1984), "A method for minimizing the impact of distributional assumptions in econometric models for duration data" Econometrica, 52, 271-320.

[8] Holm, P., Kyyrä, T., and J. Rantala (1999): "Household economic incentives, the unemployment trap and the probability of finding a job", International Tax and Public Finance, 6, 361-378.

[9] Hunt, J. (1995), "The effect of unemployment compensation on unemployment duration in Germany", Journal of Labour Economics, 31(1), 88-120.

[10] Hutchens, R. (1999), "Social security benefits and employer behaviour: Evaluating social security early retirement benefits as a form of unemployment insurance", International Economic Review, 40(3), 659-678.

[11] Kalbfleisch, J. D., and R. L. Prentice (1980), The Statistical Analysis of Failure Time Data, New York: Wiley.

[12] Kaplan, E. L., and P. Meier (1958), "Nonparametric estimation from incomplete observations", Journal of the American Statistical Association, 53, 457-481.

[13] Koenker, R., and Y. Bilias (2001), "Quantile regression for duration data: a reappraisal of the Pennsylvania reemployment bonus experiments", Empirical Economics, 26, 199-220. 
[14] Koenker, R., and O. Geling (2001), "Reappraising medfly longetivity: a quantile regression survival analysis", Journal of the American Statistical Association, 96(454), 458-468.

[15] Koenker, R., and Z. Xiao (2002), "Inference on the quantile regression process", Econometrica, 70(4), 1583-1612.

[16] Koskela, E., and R. Uusitalo (2003), "The un-intended convergence: How the Finnish unemployment reached the European level", The Labour Institute for Economic Research, Discussion Papers No. 188, Helsinki.

[17] Lüdemann, E., R. Wilke and X. Zhang (2004), "Censored quantile regressions and the length of unemployment periods in West Germany", ZEW-Discussion Paper, No. 04-57.

[18] Meyer, B. D. (1990), "Unemployment insurance and unemployment spells", Econometrica, 58, 757-782.

[19] OECD (2004), "Ageing and employment policies: Finland", Paris.

[20] Rantala, J. (2002), "Unemployment among the elderly and unemployment pension" (in Finnish), Central Pension Security Institute, Reports 2002:28, Helsinki.

[21] Rantala, J. (2003), "Income changes associated with retirement" in Subsistence of pensioners in the 1990s (in Finnish), eds. R. Hagfors, K. Hellsten, S. Ilmakunnas, and H. Uusitalo, Central Pension Security Institute, Research Publications, 2003:1, Helsinki.

[22] Rantala, J., and A. Romppanen (2004), "Labour force participation of the elderly" (in Finnish), Central Pension Security Institute, Reports, 2004:35, Helsinki. 
Table 5: Cox PH model estimates for exits to employment

\begin{tabular}{|c|c|c|}
\hline & \multicolumn{2}{|c|}{ Model specification } \\
\hline & (1) & (2) \\
\hline Married & $.2345(.0520)$ & $.2735(.0521)$ \\
\hline Female & $-.1091(.0654)$ & $-.0531(.0662)$ \\
\hline Female $\times$ married & $-.3122(.0752)$ & $-.3742(.0754)$ \\
\hline Dependent child & $.1741(.0445)$ & $.1773(.0448)$ \\
\hline Swedish speaking & $.2826(.0713)$ & $.2633(.0715)$ \\
\hline \multicolumn{3}{|l|}{ Occupation: } \\
\hline Technical & $.1608(.0749)$ & $.1821(.0754)$ \\
\hline Teacher, lawyer, humanist & $.3095(.1070)$ & $.3162(.1072)$ \\
\hline Health care & $.8557(.1258)$ & $.8790(.1261)$ \\
\hline Clerical work & $-.2765(.0617)$ & $-.2667(.0621)$ \\
\hline Forest work, farming, fishing & $.8411(.1084)$ & $.6085(.1100)$ \\
\hline Transportation & $.1338(.0747)$ & $.1220(.0752)$ \\
\hline Industrial work & $.2381(.0538)$ & $.1671(.0549)$ \\
\hline Service work & $-.0825(.0756)$ & $-.1328(.0758)$ \\
\hline Not classified & $.1010(.2049)$ & $.0740(.2076)$ \\
\hline Full experience & & $-.2460(.0610)$ \\
\hline Unemployed in early 1990s & & $.3308(.0385)$ \\
\hline Past recall in early 1990s & & $.7922(.0532)$ \\
\hline Disabled & & $-.8602(.1237)$ \\
\hline Unemployment started in winter time & & $.1354(.0344)$ \\
\hline log Unemployment benefit & & $-.3561(.0152)$ \\
\hline
\end{tabular}

Notes: The regression parameters are estimated with the Cox partial likelihood method, the ties dealt with the Breslow approximation. Standard errors are in parentheses. The baseline hazard is allowed to vary freely across age groups (50-52, 53-54, and 55-57) and the sampling year (1996 and 1997). The number of observations is 12,523 . The reference occupation is commercial work. 
Figure 6: QR estimates from the basic model
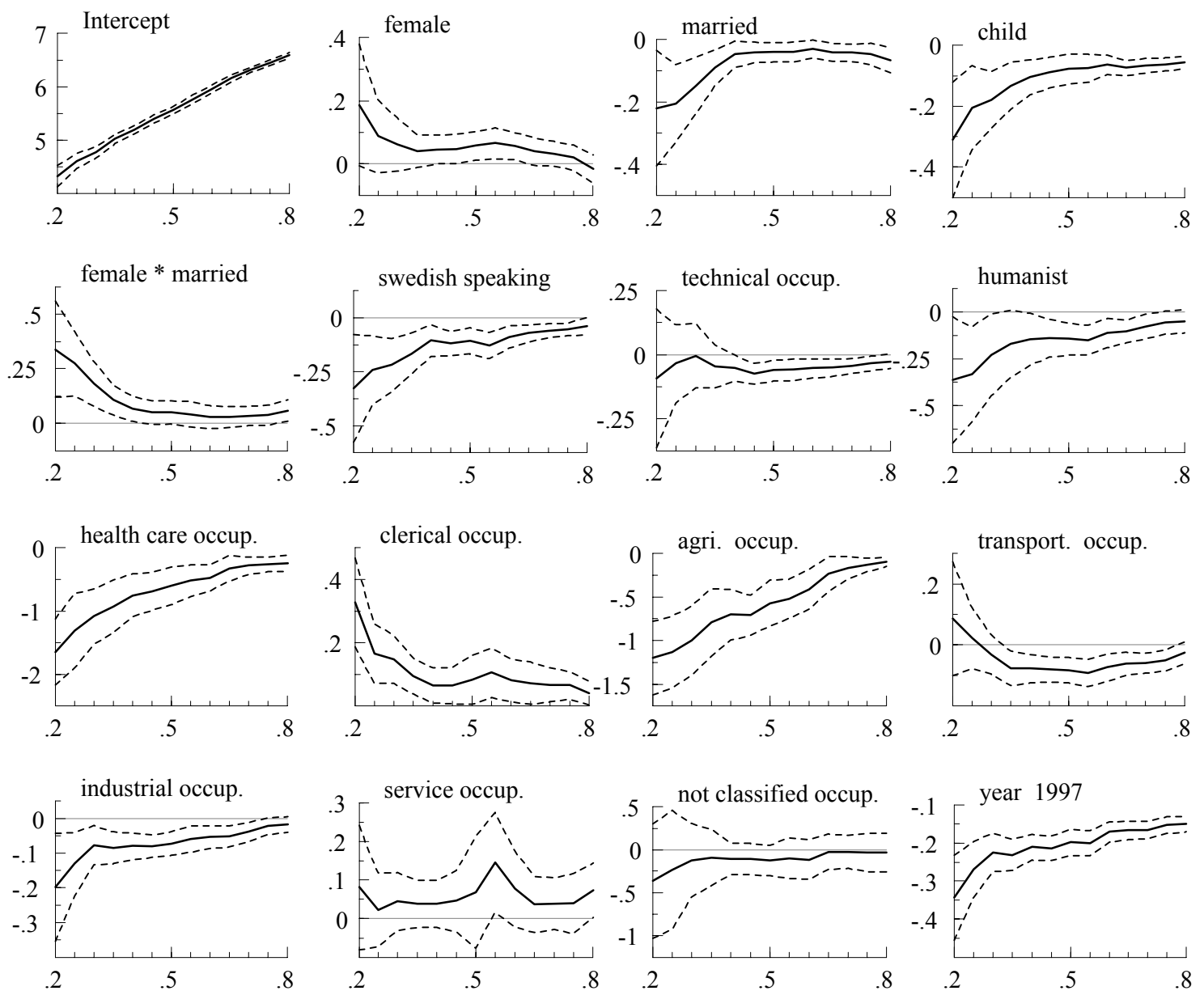

age group 55-57

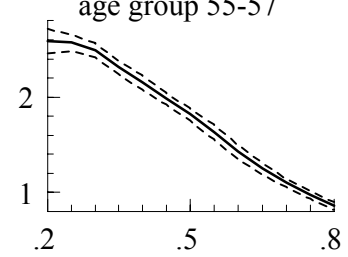


Figure 7: QR estimates from the unobserved heterogeneity model
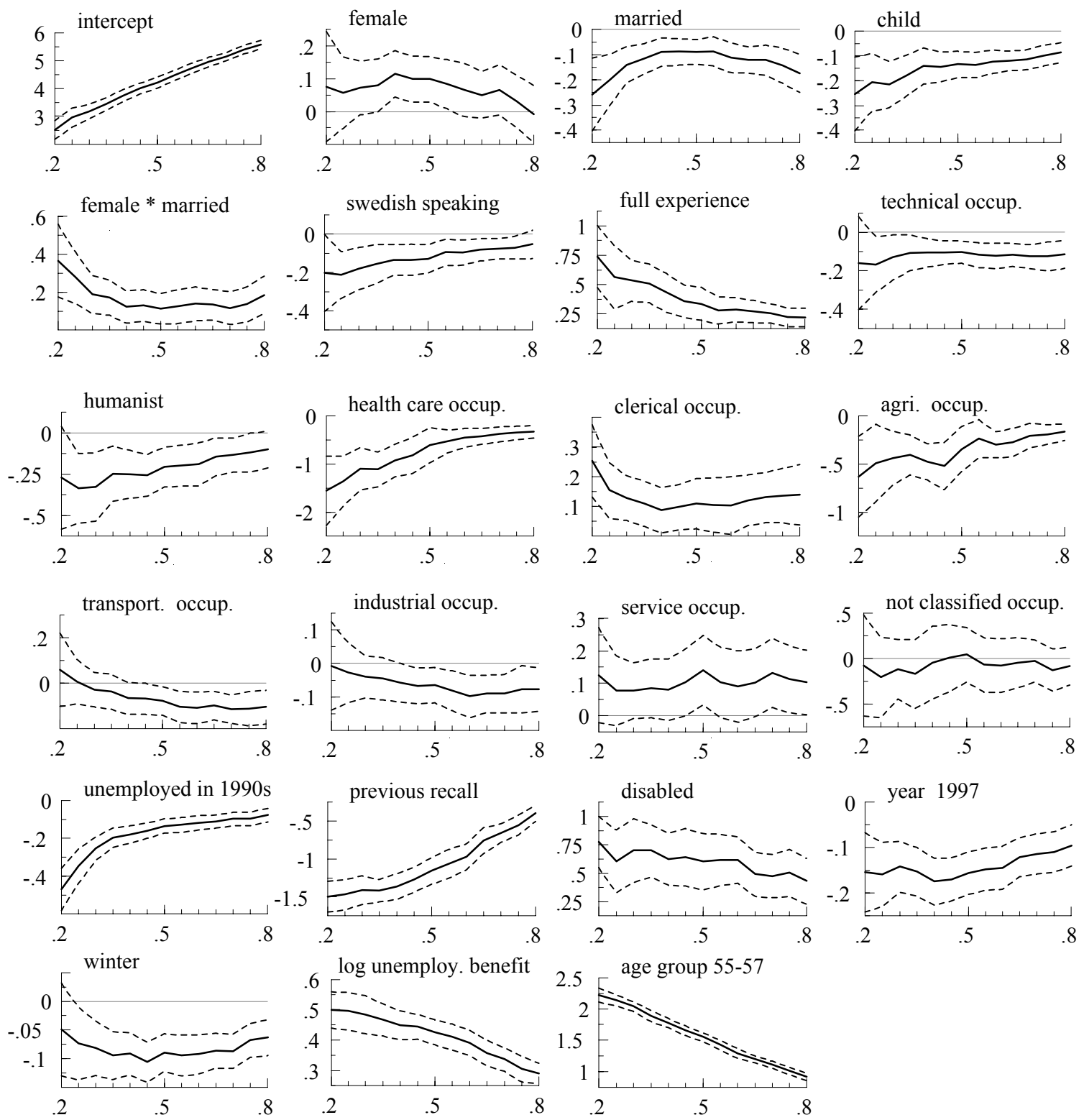